\title{
PÓS-GRADUAÇÃO EM DESENVOLVIMENTO REGIONAL NA UNIVERSIDADE DE SANTA CRUZ DO SUL - 20 ANOS
}

\author{
POSTGRADUATE PROGRAM IN REGIONAL DEVELOPMENT \\ AT THE UNIVERSITY OF SANTA CRUZ DO SUL - 20 YEARS
}

\author{
Virginia Elisabeta Etges \\ Universidade de Santa Cruz do Sul - RS - Brasil \\ Mizael Dornelles \\ Universidade de Santa Cruz do Sul - RS - Brasil
}

\begin{abstract}
Resumo: O Programa de Pós-Graduação em Desenvolvimento Regional da Universidade de Santa Cruz do Sul - UNISC completou 20 anos em 2014. Criado em 1994, em nível de mestrado, esteve originalmente vinculado ao Comitê Multidisciplinar da CAPES, tendo sido o primeiro Programa da área no país. Em 2002 passou por uma reestruturação, vinculando-se, a partir de então, ao Comitê do Planejamento Urbano e Regional/Demografia. Com a obtenção da nota 4, em 2004, passou a oferecer o nível de Doutorado a partir de 2005 . Em 2010 passou por uma segunda reestruturação, culminando com a obtenção da nota 5 na avaliação trienal de 2013. Neste artigo apresentamos referenciais teórico-metodológicos que orientam a discussão sobre desenvolvimento regional, realizada no âmbito do Programa ao longo dos 20 anos, juntamente com dados que demonstram a trajetória e os resultados alcançados no período.
\end{abstract}

Palavras-chave: Desenvolvimento Regional. Pesquisa. Pós-Graduação.

Abstract: The Postgraduate Program in Regional Development from the University of Santa Cruz do Sul - UNISC completed 20 years in 2014. Created in 1994, at a Master Degree level, it was originally linked to CAPES' multidisciplinary committee, being the first program in the country in the area. In 2002 it was restructured, being related, since then, to the Regional/Demography and Urban Planning Committee. After receiving a grade 4 during the CAPES evaluation process, in 2004, the program has also started offering a Doctorate Degree after 2005. In 2010 it was restructured a second time, culminating with the grade 5 ranking from CAPES during their triennial evaluation. In this article are presented the theoretical-methodological references that lead the discussion about regional development, which occurred in the program throughout the last 20 years, along with data that show the trajectory and the results that were achieved during this period.

Keywords: Regional Development. Research. Postgraduate.

\section{Introdução}

O Programa de Pós-Graduação em Desenvolvimento Regional - PPGDR, da Universidade de Santa Cruz do Sul - UNISC, completou 20 anos em 2014. Criado em 1994, o Programa integrou o conjunto de ações implementadas por ocasião do reconhecimento da Universidade de Santa Cruz do Sul, ocorrido em 1993.

O primeiro curso superior em Santa Cruz do Sul foi instalado em 1964, tendo como mantenedora a Associação Pró-Ensino em Santa Cruz do Sul - APESC. Nos anos seguintes outros cursos foram criados, atendendo a uma demanda dos 
jovens da região, até então suprida pela UFSM, em Santa Maria, e pela UFRGS e PUC/RS, em Porto Alegre.

Com o reconhecimento da Universidade pelo MEC, em junho de 1993, aprofunda-se o compromisso da instituição com o desenvolvimento da sua região de abrangência, contexto em que o PPGDR foi gestado.

Implementado em nível de mestrado, esteve originalmente vinculado ao Comitê Multidisciplinar da CAPES, tendo sido o primeiro Programa da área do Desenvolvimento Regional no país. Em 2002 passou por uma reestruturação, vinculando-se, a partir de então, ao Comitê do Planejamento Urbano e Regional/Demografia. Com a obtenção da nota 4 em 2004, habilitou-se a oferecer o nível de Doutorado, o qual foi implementado a partir de 2005. Em 2010 passou por uma segunda reestruturação, culminando com a obtenção da nota 5 na avaliação trienal de 2013.

Nesse artigo apresenta-se, além da trajetória do Programa, referenciais teórico-metodológicos que orientam a discussão sobre o tema, bem como dados sobre o perfil dos alunos e as dissertações e teses aprovadas ao longo do período.

\section{A trajetória do Programa e seu referencial teórico-metodológico}

As discussões em torno do tema desenvolvimento regional, no contexto da realidade brasileira, ao longo do século $X X$, fundamentaram-se em parâmetros que foram definidores do alcance e da eficácia dos resultados alcançados.

A atenção dispensada ao tema durante as décadas de 1980/90 no país era inexpressiva. Somente na virada do milênio o tema volta a receber atenção, com a criação do Ministério da Integração, em 1999, e a formulação da Política Nacional de Desenvolvimento Regional - PNDR em 2003.

No Rio Grande do Sul, entretanto, o tema estava em destaque, principalmente a partir da década de 1990, na medida em que várias iniciativas voltadas à descentralização dos processos de promoção de desenvolvimento foram implementadas, como a instalação dos Polos de Modernização Tecnológica, dos Conselhos Regionais de Desenvolvimento - COREDES, bem como o importante papel das Universidades Comunitárias, enquanto fomentadoras do desenvolvimento de suas regiões de abrangência.

É neste contexto de descentralização dos processos de gestão do território e de promoção do desenvolvimento que a Universidade de Santa Cruz do Sul instala o Programa de Pós-Graduação em Desenvolvimento Regional, com o objetivo de torná-lo um centro de referência nos debates e na produção de conhecimento a respeito do tema.

O referencial teórico-metodológico que orienta a pesquisa no Programa parte da compreensão de que regiões existem e, como tais, expressam as diversas formas de apropriação e uso do território pela sociedade.

No contexto do desenvolvimento regional entende-se a região como parte de uma totalidade (LENCIONI, 1999), totalidade não mais orgânica ou lógica, nem 
uma totalidade harmônica, e sim uma totalidade histórica, entendida à luz da concepção de Formação Econômico-Social - ou Formação Sócio-Espacial, nas palavras de Milton Santos (1996).

Assim, a diferenciação de áreas, resultante tanto de processos da natureza como de processos sociais, e que se constitui na base da possibilidade de se poder falar de região, não está associada à ideia de singularidade, que entende-se vinculada ao conceito de lugar, e sim à ideia de particularidade, isto é, uma mediação entre o universal (processos gerais advindos da globalização) e o singular (a especificação máxima do universal). (CORREA, 1997).

Trata-se, portanto, de entender a diversidade regional como potencialidade para a promoção do desenvolvimento regional ou, como afirma Tania Bacelar de Araújo (2000, p. 127), "[...] é preciso pensar e agir no Brasil heterogêneo e diversificado, tratar como positivo, como potencialidade (e não como problema) a crescente diferenciação das diversas porções do país."

Uma região, para que exista de fato, segundo Boisier (1999), tem que ser construída socialmente, a partir de laços comuns, de traços de identidade que se expressam no âmbito do cultural, do econômico e do político, que permitam vislumbrar desafios comuns à comunidade envolvida. Construir socialmente uma região significa potencializar sua capacidade de auto-organização, transformando uma sociedade inanimada, segmentada por interesses setoriais, pouco perceptiva de sua identidade territorial e definitivamente passiva, em outra, organizada, coesa, consciente de sua identidade, capaz de mobilizar-se em torno de projetos políticos comuns, ou seja, capaz de transformar-se em sujeito de seu próprio desenvolvimento.

Frente a esses desafios, o Programa em sua trajetória de 20 anos, passou por três fases. Na primeira fase (1994-2002) era constituído por quatro Áreas de Concentração, que eram: Área Sócio-Cultural; Área Econômico-Organizacional; Área Tecno-Ambiental e Área Político-Institucional. Na segunda fase (2003-2010) estas áreas foram suprimidas, com a criação de uma única Área de Concentração, em Desenvolvimento Regional, com três Linhas de Pesquisa, a saber: Desenvolvimento e Integração Regional; Desenvolvimento, Ordenamento Territorial e Meio Ambiente; e Sociedade, Políticas Públicas e Desenvolvimento Regional.

A terceira fase, iniciada em 2011, mantem a Área de Concentração em Desenvolvimento Regional, através da qual vem fomentando e consolidando pesquisas de caráter interdisciplinar, atentas às mudanças inerentes ao movimento das instituições econômicas, das organizações políticas da esfera estatal e da sociedade civil, às mudanças tecnológicas e ambientais, bem como as alterações próprias às esferas jurídica e simbólica, que normatizam e orientam o universo das representações das comunidades regionais.

Para tanto apresenta três Linhas de Pesquisa:

a) Território, Planejamento e Sustentabilidade - Abrange um conjunto de temas relacionados à compreensão da dinâmica territorial, considerando as diferentes escalas de ação e de análise dos processos socioespaciais, a diversidade histórico-cultural do território, as estratégias e os instrumentos 
de gestão e de planejamento territorial, nas distintas dimensões de sustentabilidade envolvidas.

b) Estado, Instituições e Democracia - Enfoca o estudo das capacidades institucionais em seus vários níveis, de tomar iniciativa, mediar e regular os processos de gestão do território. Analisa conflitos, tensões e produção de consensos entre poder público e agentes sociais.

c) Organizações, Mercado e Desenvolvimento - Dedica-se à análise da atividade produtiva regional com destaque para agentes e organizações sociais e econômicas, formas de cooperação e conflitos, configurados em distintos modos de organização da produção e do mercado.

O Programa também vem empenhando esforços para constituir-se em um Centro de Excelência em estudos e informações sobre o Desenvolvimento Regional, através da criação do Observatório do Desenvolvimento Regional ObservaDR, instalado em 2012, com o objetivo de articular centros de pesquisa, instituições públicas e entidades regionais, visando estabelecer uma rede de pesquisa e de extensão acerca de questões teórico-metodológicas, bem como contribuir para a reflexão e a interação institucional sobre processos, dinâmicas e políticas regionais de desenvolvimento no país.

\section{Sobre as Teses e Dissertações defendidas no PPGDR}

Durante o período de 1994 a $2014^{1}$ foram defendidas 314 dissertações de mestrado e 52 teses de doutoramento. Assim, instigados pelos resultados desta produção científica, desde as primeiras defesas, procurou-se identificar algumas características gerais e outras particulares relativas às dissertações e teses, bem como sobre a trajetória dos mestres e doutores em Desenvolvimento Regional pela UNISC.

Os dados apresentados foram coletados nas dissertações e teses defendidas no período, acrescidos de informações extraídas dos currículos Lattes dos mestres e doutores pelo PPGDR, disponíveis na Plataforma Lattes do CNPq.

Foram consultadas 314 dissertações e 52 teses, disponíveis junto a biblioteca Central da UNISC, no acervo da biblioteca do PPGDR, nos arquivos online do banco de dissertações e teses do Programa, e também informações referentes a inscrição dos estudantes junto a secretaria do PPGDR. Entretanto, como nem todos os mestres e doutores apresentavam currículo disponível na Plataforma Lattes e alguns tinham o currículo desatualizado, nem todas as informações correspondem ao registro total de teses e dissertações defendidas.

Os dados levantados foram referentes ao ano da defesa, o nome completo do autor, o título, o resumo, as palavras chave, a área de investigação, área de concentração e linha de pesquisa e nome completo do orientador. A partir destes dados, as dissertações e teses foram classificadas de acordo com tema (identificado

\footnotetext{
${ }^{1}$ Os dados referentes a 2014 são parciais, relativos ao primeiro semestre.
} 
a partir do título, do resumo e das palavras chave), unidade territorial investigada e gênero do autor.

A Tabela 1 apresenta o número de defesas de dissertações e teses agrupadas por ano. Observa-se que a maior concentração de defesas de dissertações ocorreu entre os anos de 1999 e 2005, apresentando redução a partir de 2006, o que se explica pela redução no número de ingressos no mestrado; já as defesas de teses apresentam um padrão mais regular a partir de 2009, ano em que os concluintes da primeira turma regular de doutorado defendem suas teses.

Tabela 1. Número de defesas por ano

\begin{tabular}{c|ccr}
\hline Ano & Dissertações & Teses & Total \\
\hline 1996 & 2 & - & 2 \\
1997 & 9 & - & 9 \\
1998 & 15 & - & 15 \\
1999 & 20 & - & 20 \\
2000 & 29 & - & 29 \\
2001 & 33 & - & 33 \\
2002 & 19 & - & 19 \\
2003 & 20 & - & 20 \\
2004 & 22 & - & 22 \\
2005 & 22 & $1^{*}$ & 23 \\
2006 & 11 & $3^{*}$ & 14 \\
2007 & 18 & $3^{*}$ & 21 \\
2008 & 15 & $1^{*}$ & 16 \\
2009 & 15 & 5 & 20 \\
2010 & 15 & 10 & 25 \\
2011 & 17 & 5 & 22 \\
\hline 2012 & 15 & 12 & 27 \\
2013 & 14 & 9 & 23 \\
\hline 2014 & $3^{* *}$ & $3^{* *}$ & $6^{* *}$ \\
Total & 314 & 52 & 366 \\
\hline
\end{tabular}

*Estas defesas resultam de oferta especial de vagas em nível de doutorado, autorizada pela CAPES em 2002.

**Dados parciais, relativos ao primeiro semestre.

Fonte: Banco de Teses e Dissertações do PPGDR Elaborado pelos autores

A Tabela 2 classifica as dissertações e teses de acordo com as áreas de concentração e linhas de pesquisa propostas pelo PPGDR. As quatro áreas de concentração, mantidas pelo Programa no período de 1994 até 2002 foram: Sociocultural; Econômico-Organizacional; Tecno-Ambiental2; e PolíticoInstitucional ${ }^{3}$. A partir de 2003 foi criada uma única Área de Concentração, com três Linhas de Pesquisa: Desenvolvimento e Integração Regional; Desenvolvimento, Ordenamento Territorial e Meio Ambiente; e Sociedade, Políticas Públicas e Desenvolvimento Regional. Com a reestruturação do Programa, realizada em 2010,

\footnotetext{
${ }^{2}$ Criada em 1995.

${ }^{3}$ Criada em 1996.
} 
as Linhas de Pesquisa passaram a ser: Território, Planejamento e Sustentabilidade; Estado, Instituições e Democracia; e Organizações, Mercado e Desenvolvimento.

No primeiro período (1994-2002) a Área de Concentração Sócio-Cultural destaca-se dentro do Programa. Na sequência (entre 2003-2010), os temas relacionados à 'Sociedade, Políticas Públicas e Desenvolvimento Regional' têm maior ênfase. Na terceira fase, as linhas de pesquisa, 'Território, Planejamento e Sustentabilidade' e 'Organizações, Mercado e Desenvolvimento' respectivamente, se destacam.

Tabela 2. Número de defesas por áreas de concentração (1994-2002) e linhas de pesquisa (2003-2010 e 2011-2014)

\begin{tabular}{|c|c|c|c|c|c|}
\hline \multicolumn{2}{|c|}{ Áreas de concentração e Linhas de pesquisa } & \multirow{2}{*}{$\begin{array}{l}\text { Dissertações } \\
44\end{array}$} & \multirow{2}{*}{$\begin{array}{c}\text { Teses } \\
-\end{array}$} & \multicolumn{2}{|c|}{ Total } \\
\hline \multirow{5}{*}{$\begin{array}{l}\text { Áreas de concentração } \\
\text { (1994-2002) }\end{array}$} & Sócio-Cultural & & & 44 & $12.0 \%$ \\
\hline & Econômico-Organizacional & 33 & - & 33 & $9.0 \%$ \\
\hline & Tecno-Ambiental & 26 & - & 26 & $7.2 \%$ \\
\hline & Político-Institucional & 25 & - & 25 & $6.8 \%$ \\
\hline & Subtotal & 128 & - & 128 & $35.0 \%$ \\
\hline \multirow{4}{*}{$\begin{array}{l}\text { Linhas de pesquisa } \\
(2003-2010)\end{array}$} & $\begin{array}{l}\text { Desenvolvimento e Integração } \\
\text { Regional }\end{array}$ & 34 & 9 & 43 & $11.7 \%$ \\
\hline & $\begin{array}{l}\text { Desenvolvimento, Ordenamento } \\
\text { Territorial e Meio Ambiente }\end{array}$ & 28 & 7 & 35 & $9.6 \%$ \\
\hline & $\begin{array}{l}\text { Sociedade, Políticas Públicas e } \\
\text { Desenvolvimento Regional }\end{array}$ & 75 & 7 & 82 & $22.4 \%$ \\
\hline & Subtotal & 137 & 23 & 160 & $43.7 \%$ \\
\hline \multirow{4}{*}{$\begin{array}{l}\text { Linhas de pesquisa } \\
\text { (2011-2014) }\end{array}$} & $\begin{array}{l}\text { Território, Planejamento e } \\
\text { Sustentabilidade }\end{array}$ & 21 & 13 & 34 & $9.3 \%$ \\
\hline & Estado, Instituições e Democracia & 11 & 4 & 15 & $4.1 \%$ \\
\hline & $\begin{array}{l}\text { Organizações, Mercado e } \\
\text { Desenvolvimento }\end{array}$ & 17 & 12 & 29 & $7.9 \%$ \\
\hline & Subtotal & 49 & 29 & 78 & $21.3 \%$ \\
\hline Total & & 314 & 52 & 366 & $100.0 \%$ \\
\hline
\end{tabular}

Fonte: Banco de Teses e Dissertações do PPGDR - Elaborado pelos autores.

As dissertações e teses foram agrupadas por grandes temas, a partir dos quais foi elaborada a Tabela 3, também apresentada em forma de ranking. Essa definição temática foi dada a partir da interpretação, notadamente, dos títulos, dos resumos e das palavras-chave das pesquisas. 
Tabela 3. Número de defesas por tema

\begin{tabular}{l|ccr}
\hline Temas & Dissertações & Teses & Total \\
\hline Políticas públicas & 26 & 10 & 36 \\
Saúde & 34 & - & 34 \\
Organizações & 28 & 6 & 34 \\
Meio rural & 27 & 3 & 30 \\
Educação & 29 & 1 & 30 \\
Meio ambiente & 24 & 2 & 26 \\
\hline Território & 8 & 9 & 17 \\
Desenvolvimento e Sociedade & 11 & 5 & 16 \\
\hline Tecnologia & 14 & 1 & 15 \\
Meio urbano & 15 & - & 15 \\
Turismo & 11 & 3 & 14 \\
\hline Trabalho & 13 & 1 & 14 \\
Processos participativos & 11 & 3 & 14 \\
Economia & 8 & 5 & 13 \\
Comunicação & 12 & - & 12 \\
Cultura e identidade & 10 & 1 & 11 \\
\hline Movimentos sociais & 7 & - & 7 \\
Jovens & 7 & - & 7 \\
\hline Mercado & 5 & 1 & 6 \\
\hline Terceira idade & 5 & - & 5 \\
Sistema carcerário & 4 & - & 4 \\
\hline Transportes & 2 & 1 & 3 \\
\hline Esporte & 2 & - & 2 \\
Migrações & 1 & - & 1 \\
\hline Total & 314 & 52 & 366 \\
\hline Fonte: Banco de Teses e Dissertações & do PPGDR & - Elaborado \\
pelos autores. & & &
\end{tabular}

Observa-se que os temas mais abordados nas dissertações e teses foram 'Políticas Públicas', 'Saúde', 'Organizações', 'Meio rural', 'Educação', 'Meio Ambiente' e 'Território', respectivamente.

Quanto às unidades territoriais investigadas, a Tabela 4 expõe as unidades político-administrativas que foram objeto das pesquisas. A tabela também está organizada na forma de ranking.

A denominação 'região' foi utilizada para caracterizar as áreas de investigação não limitadas a um município ou Estado; 'Estado' é sinônimo de Unidade da Federação; e o termo 'Atópico' refere-se às pesquisas que não apresentaram uma unidade territorial de investigação, ou seja, que realizaram abordagens teóricas sobre temas relacionados ao Desenvolvimento Regional. 
Tabela 4. Número de defesas por unidade territorial investigada

\begin{tabular}{l|ccr}
\hline Unidade territorial & Dissertações & Teses & Total \\
\hline Região & 147 & 30 & 177 \\
\hline Município & 127 & 9 & 136 \\
\hline Estado & 14 & 5 & 19 \\
Atópico & 14 & 1 & 15 \\
País & 6 & 2 & 8 \\
Macrorregião & 4 & 3 & 7 \\
Internacional & 2 & 2 & 4 \\
Total & 314 & 52 & 366 \\
\hline Fonte: Banco de Teses e Dissertações do PPGDR - \\
Elaborado pelos autores.
\end{tabular}

A Tabela 4.1 trata da localização das áreas investigadas nos Estados brasileiros. Verifica-se que há um predomínio de estudos realizados no Estado do Rio Grande do Sul, mas destaca-se também os estudos realizados em outras 11 Unidades da Federação.

Tabela 4.1 Localização das áreas investigadas nos Estados brasileiros

\begin{tabular}{l|ccr}
\hline Estado & Dissertações & Teses & \multicolumn{1}{c}{ Total } \\
\hline AM & - & 2 & 2 \\
AP & - & 1 & 1 \\
MA & 1 & 1 & 2 \\
MG & 1 & - & 1 \\
MT & - & 2 & 2 \\
PA & 2 & - & 2 \\
PR & - & 1 & 1 \\
RO & - & 2 & 2 \\
RS & 273 & 31 & 304 \\
SC & 8 & - & 8 \\
RS e CE & 1 & 1 & 2 \\
RS e SC & - & 2 & 3 \\
RS, SC e PR & 287 & 1 & 1 \\
Total & de & 44 & 331 \\
\hline Fonte: Bancos & e & Dissertações & do \\
PPGDR - Elaborado pelos autores. & &
\end{tabular}

A Tabela 4.2 procura detalhar as regiões, apresentando-as por nome. Ressalta-se que na categoria 'Região' aparecem estudos associados a um município. Nestes casos o trabalho referia-se a determinado município e sua região de influência. Os estudos relativos à 'Região' e 'Município' que apresentaram uma ocorrência apenas foram agrupados em 'Outros'. 
Tabela 4.2 Detalhamento das unidades territoriais investigadas

\begin{tabular}{|c|c|c|c|c|}
\hline Unidade territorial & Área investigada & Dissertações & Teses & Total \\
\hline \multirow{21}{*}{ Região } & Coordenadoria Regional de Saúde $13^{a}$ & 1 & 1 & 2 \\
\hline & Bacia hidrográfica do Rio Pardinho-RS & 2 & - & 2 \\
\hline & Bacia hidrográfica do Rio Pardo-RS & 2 & - & 2 \\
\hline & Diocese Santa Cruz do Sul & 2 & - & 2 \\
\hline & Fronteira Oeste & 2 & - & 2 \\
\hline & Gramado-RS e Canela-RS & 2 & - & 2 \\
\hline & Médio Alto Uruguai-RS & 2 & 1 & 3 \\
\hline & Metade Sul do RS & 2 & 1 & 3 \\
\hline & Noroeste do RS & 1 & 1 & 2 \\
\hline & Norte do RS & 1 & 1 & 2 \\
\hline & Porto Alegre & 3 & 1 & 4 \\
\hline & Quarta Colônia Italiana-RS & 2 & - & 2 \\
\hline & Santa Cruz do Sul-RS & 26 & 1 & 27 \\
\hline & Santa Cruz do Sul-RS e Venâncio Aires-RS & 2 & - & 2 \\
\hline & Santa Maria-RS & 2 & - & 2 \\
\hline & Santana do Livramento-RS & 1 & 1 & 2 \\
\hline & Vale do Paranhana-RS & 1 & 1 & 2 \\
\hline & Vale do Rio Pardo-RS & 38 & 1 & 39 \\
\hline & Vale do Taquari-RS & 9 & - & 9 \\
\hline & Vales do Rio Pardo-RS e Vale do Taquari-RS & 2 & 1 & 3 \\
\hline & Outros* & 43 & 18 & 61 \\
\hline \multirow{13}{*}{ Município } & Cachoeira do Sul-RS & 2 & - & 2 \\
\hline & Candelária-RS & 2 & - & 2 \\
\hline & Charqueadas-RS & 2 & - & 2 \\
\hline & Ijuí-RS & 2 & 1 & 3 \\
\hline & Lajeado-RS & 2 & - & 2 \\
\hline & Passo Fundo-RS & 2 & - & 2 \\
\hline & Rio Pardo-RS & 5 & - & 5 \\
\hline & Santa Cruz do Sul-RS & 77 & 2 & 79 \\
\hline & Santa Maria-RS & 4 & 2 & 6 \\
\hline & São Leopoldo-RS & 2 & - & 2 \\
\hline & Venâncio Aires-RS & 3 & 1 & 4 \\
\hline & Vera Cruz-RS & 4 & - & 4 \\
\hline & Outros* & 19 & 3 & 22 \\
\hline \multirow{3}{*}{ Estado } & RS & 14 & 5 & 19 \\
\hline & PR & - & 1 & 1 \\
\hline & SC & 1 & - & 1 \\
\hline Atópico & - & 15 & 1 & 16 \\
\hline País & Brasil & 6 & 2 & 8 \\
\hline \multirow{2}{*}{ Macrorregiões } & Centro-Oeste & 1 & - & 1 \\
\hline & Região Sul & 3 & 3 & 6 \\
\hline \multirow{4}{*}{ Internacional } & Brasil e Argentina & - & 1 & 1 \\
\hline & Brasil e Portugal & - & 1 & 1 \\
\hline & Brasil e Uruguai & 1 & - & 1 \\
\hline & MERCOSUL & 1 & - & 1 \\
\hline Total & - & 314 & 52 & 366 \\
\hline
\end{tabular}

* Regiões ou municípios que aparecem somente uma vez somados.

Fonte: Banco de Teses e Dissertações do PPGDR - Elaborado pelos autores.

Observa-se que as unidades territoriais investigadas foram predominantemente regiões e municípios $(85,52 \%)$, com grande concentração no Estado do Rio Grande do Sul, sendo que as regiões mais pesquisadas foram as de 
Santa Cruz do Sul-RS e Vale do Rio Pardo-RS, enquanto o município mais pesquisado também foi o de Santa Cruz do Sul-RS.

\section{Considerações sobre os autores - Mestres e Doutores egressos do PPGDR}

As informações disponíveis para este item foram coletadas na Plataforma Lattes, através do acesso ao currículo de cada um dos autores. Cabe destacar que 3 currículos detinham informações incompletas e 24 não foram encontrados, sendo estes classificados, respectivamente, como incompletos e indisponíveis.

Com base nas consultas realizadas no primeiro semestre de 2014, sobre os autores, foi possível identificar: ano da última atualização do Currículo Lattes, formação (curso de graduação); organização (Universidade onde cursou a graduação) e município sede; vínculo empregatício em 2014 e município sede; e para os egressos que defenderam suas dissertações no PPGDR também foi apontado se fizeram doutorado, em que ano (concluído ou em curso) e onde (Universidade).

Sobre a atualização do Currículo na Plataforma Lattes, pode-se verificar que pouco mais da metade $(52,7 \%)$, dos Mestres e Doutores pelo PPGDR, apresentaram o currículo atualizado em 2014 e $29.5 \%$ haviam realizado a última atualização entre 2010 e 2013, conforme a Tabela 5.

Tabela 5. Número de autores por ano de atualização do Currículo na Plataforma Lattes

\begin{tabular}{l|ccrr}
\hline Atualização & Mestres & Doutores & \multicolumn{2}{c}{ Total } \\
\hline 2014 & 152 & 41 & 193 & $52.7 \%$ \\
2013 & 50 & 5 & 55 & $15.0 \%$ \\
2012 & 33 & 2 & 35 & $9.6 \%$ \\
2011 & 10 & - & 10 & $2.7 \%$ \\
2010 & 7 & 1 & 8 & $2.2 \%$ \\
Anterior a 2010 & 35 & 3 & 38 & $10.4 \%$ \\
Incompleto & 3 & - & 3 & $0.8 \%$ \\
Indisponível & 24 & - & 24 & $6.6 \%$ \\
Total & 314 & 52 & 366 & $100.0 \%$ \\
\hline
\end{tabular}

Fonte: Plataforma Lattes CNPq - Elaborado pelos autores.

Os Mestres e Doutores egressos do PPGDR foram classificados por gênero, conforme a Tabela 6. Observa-se que o doutorado apresenta um maior número de homens, enquanto o Mestrado é mais procurado por mulheres. No total, entretanto, foi o mesmo número de homens e mulheres que procuraram o programa, segundo consulta nas publicações disponíveis até o primeiro semestre de 2014.

Tabela 6. Número de Mestres e Doutores por gênero

\begin{tabular}{l|ccr}
\hline Autores & Homens & Mulheres & \multicolumn{1}{c}{ Total } \\
\hline Mestres & 151 & 163 & 314 \\
Doutores & 32 & 20 & 52 \\
Total & 183 & 183 & 366 \\
\hline
\end{tabular}

Fonte: Secretaria do PPGDR - Elaborado pelos autores. 
Pode-se conferir na Tabela 7, que quase metade, 42,3\% dos Mestres e Doutores que procuraram o PPGDR nesses 20 anos têm formação na área de Ciências Sociais Aplicadas e $21 \%$ tem têm formação em Ciências Humanas, segundo as 'Grandes Áreas do Conhecimento', definidas pelo CNPq.

Tabela 7. Área de formação/graduação dos Mestres e Doutores por Grandes Áreas do Conhecimento

\begin{tabular}{l|ccrr}
\hline Grandes Áreas do Conhecimento & Mestres & Doutores & \multicolumn{2}{c}{ Total } \\
\hline Ciências Exatas e da Terra & 10 & - & 10 & $2.94 \%$ \\
Ciências Biológicas & 13 & 3 & 16 & $4.71 \%$ \\
Engenharias & 2 & 1 & 3 & $0.88 \%$ \\
Ciências da Saúde & 41 & 2 & 43 & $12.65 \%$ \\
Ciências Agrárias & 10 & 1 & 11 & $3.24 \%$ \\
Ciências Sociais Aplicadas & 124 & 34 & 158 & $46.47 \%$ \\
Ciências Humanas & 70 & 7 & 77 & $22.65 \%$ \\
Linguística, Letras e Artes & 10 & - & 10 & $2.94 \%$ \\
Outros & 3 & 1 & 4 & $1.18 \%$ \\
Tecnólogo & 5 & 3 & 8 & $2.35 \%$ \\
Total & 288 & 52 & 340 & $100.00 \%$ \\
\hline
\end{tabular}

Foram desconsiderados 26 currículos.

Fonte: Plataforma Lattes CNPq - Elaborado pelos autores.

A Tabela 8 mostra os principais Cursos de Graduação dos Mestres e Doutores que passaram pelo Programa. Com maior destaque aparecem Cursos relacionados às 'Ciências Sociais Aplicadas' (Administração, Ciências Contábeis e Economia), seguidas pelas 'Ciências Humanas'. Os 13 cursos apresentados nesta tabela representam mais que $63 \%$ da formação/graduação dos mestres e 9 destes cursos contabilizam mais de $80 \%$ da formação/graduação dos doutores que procuraram o PPGDR. A Tabela 8 foi organizada na forma de ranking para ilustrar as 10 maiores ocorrências.

Tabela 8. Número de Mestres e Doutores por curso de formação/graduação (10 maiores ocorrências)

\begin{tabular}{ll|ccr}
\hline Disciplina/Curso & Mestres & Doutores & Total \\
\hline $1^{\circ}$ & Administração & 38 & 15 & 53 \\
$2^{\circ}$ & Ciências Contábeis & 17 & 8 & 25 \\
$3^{\circ}$ & Economia & 16 & 7 & 23 \\
$4^{\circ}$ & História & 16 & 5 & 21 \\
$5^{\circ}$ & Direito & 18 & 2 & 20 \\
$6^{\circ}$ & Psicologia & 19 & - & 19 \\
$7^{\circ}$ & Geografia & 15 & 1 & 16 \\
$8^{\circ}$ & Educação Física & 13 & 1 & 14 \\
\multirow{2}{*}{$9^{\circ}$} & Enfermagem & 12 & 1 & 13 \\
\cline { 2 - 4 } & Arquitetura & 13 & - & 13 \\
\multirow{2}{*}{$1^{\circ}$} & Biologia & 6 & 2 & 8 \\
\cline { 2 - 5 } Total & Pedagogia & 8 & - & 8 \\
\hline
\end{tabular}

Foram desconsiderados 26 currículos. 
Fonte: Plataforma Lattes CNPq - Elaborado pelos autores.

A Tabela 9 evidencia que nos primeiros anos o Programa teve uma procura grande por parte de egressos de cursos da UNISC. No entanto, com o passar dos anos isso foi mudando com a crescente procura por parte de egressos de universidades como UFSM, UNISINOS, PUCRS, UNIJUI e UFRGS. Esta tabela também foi organizada na forma de ranking para ilustrar as 10 maiores ocorrências.

Tabela 9. Número de Mestres e Doutores por Organização de Ensino de formação/graduação (10 maiores ocorrências)

\begin{tabular}{|c|c|c|c|c|}
\hline \multicolumn{2}{|c|}{ Organização de Ensino } & \multirow{2}{*}{$\begin{array}{c}\text { Mestres } \\
105\end{array}$} & \multirow{2}{*}{$\frac{\text { Doutores }}{3}$} & \multirow{2}{*}{$\frac{\text { Total }}{108}$} \\
\hline 10 & UNISC & & & \\
\hline $2^{\circ}$ & UFSM & 37 & 11 & 48 \\
\hline $3^{\circ}$ & UNISINOS & 17 & 3 & 20 \\
\hline $4^{\circ}$ & PUCRS & 16 & 2 & 18 \\
\hline $5^{\circ}$ & UNIJUI & 10 & 6 & 16 \\
\hline $6^{\circ}$ & UFRGS & 12 & 1 & 13 \\
\hline \multirow{4}{*}{$7^{\circ}$} & URI & 8 & - & 8 \\
\hline & UFPEL & 7 & 1 & 8 \\
\hline & UNIFRA & 7 & 1 & 8 \\
\hline & UPF & 7 & 1 & 8 \\
\hline $8^{\circ}$ & ULBRA & 6 & 1 & 7 \\
\hline $9^{\circ}$ & UCPEL & 5 & - & 5 \\
\hline \multirow{2}{*}{$10^{\circ}$} & UCS & 4 & - & 4 \\
\hline & UniRitter & 4 & - & 4 \\
\hline Tota & & 245 & 30 & 275 \\
\hline
\end{tabular}

Foram desconsiderados 25 currículos.

Fonte: Plataforma Lattes CNPq - Elaborado pelos autores.

O mapa 1 mostra a localização dos municípios em que os Mestres e Doutores pelo PPGDR obtiveram a sua Graduação. Os círculos proporcionais destacam a intensidade de ocorrências por município, categorizados em 4 faixas. Foram considerados 249 currículos de Mestres e 52 currículos de Doutores, consultados no primeiro semestre de 2014. O município de Santa Cruz do Sul-RS, seguido por Porto Alegre-RS e Santa Maria-RS, destacam-se como sedes das Universidades nas quais a maioria dos Mestres e Doutores pelo PPGDR realizaram seus cursos de Graduação. 

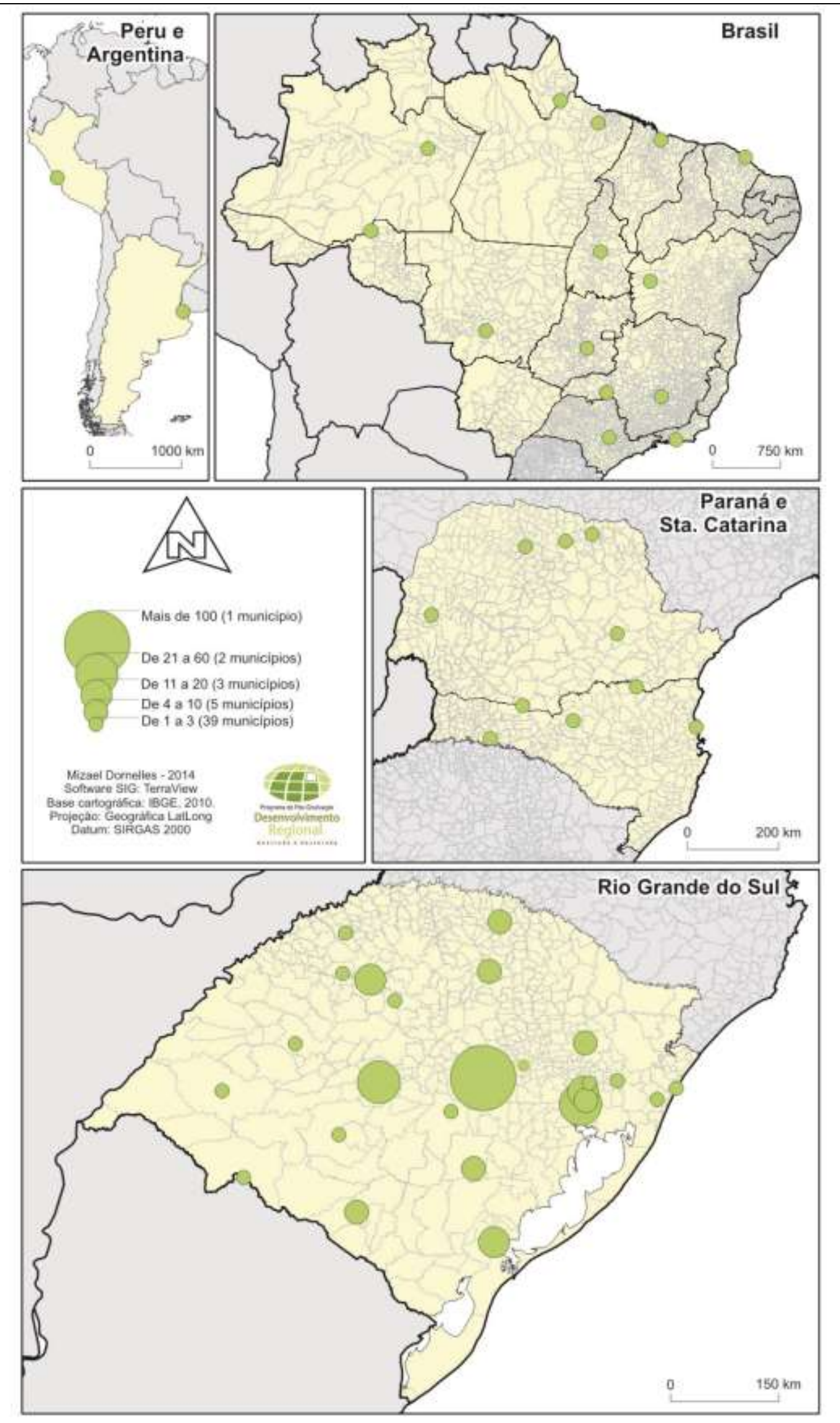

Mapa 1. Mestres e Doutores por município de Formação/graduação Fonte: Elaborado pelos autores. 
A Tabela 10 mostra as cinco principais Organizações em que os egressos do PPGDR desenvolvem suas atividades profissionais. $E$, na sequência, o mapa 2, ilustra a localização dessas Organizações no território.

Tabela 10. Número de Mestres e Doutores por organização de atuação profissional (5 maiores ocorrências)

\begin{tabular}{|c|c|c|c|c|}
\hline \multicolumn{2}{|c|}{ Organização de atuação } & \multirow{2}{*}{$\frac{\text { Mestres }}{88}$} & \multirow{2}{*}{$\frac{\text { Doutores }}{9}$} & \multirow{2}{*}{$\begin{array}{r}\text { Total } \\
97\end{array}$} \\
\hline $10^{\circ}$ & UNISC & & & \\
\hline $2^{\circ}$ & UFSM & 6 & 11 & 17 \\
\hline $3^{\circ}$ & Secretaria de Educação do RS & 6 & - & 6 \\
\hline \multirow{4}{*}{$4^{\circ}$} & UNOCHAPECÓ - SC & 5 & - & 5 \\
\hline & UNIVATES & 5 & - & 5 \\
\hline & UERGS & 4 & 1 & 5 \\
\hline & Prefeitura de Santa Cruz do Sul & 5 & - & 5 \\
\hline \multirow{4}{*}{$5^{\circ}$} & UNIPAMPA & 4 & - & 4 \\
\hline & ULBRA & 4 & - & 4 \\
\hline & FDA & 4 & - & 4 \\
\hline & FACCAT & 3 & 1 & 4 \\
\hline \multicolumn{2}{|c|}{ Total } & 134 & 22 & 156 \\
\hline
\end{tabular}

Foram desconsiderados 37 currículos.

Fonte: Plataforma Lattes CNPq - Elaborado pelos autores.

A Tabela 11 indica que 90 mestres egressos do Programa seguiram para um curso de doutorado, sendo que 28 retornaram para ao PPGDR, sendo que 15 já defenderam suas teses. Outras universidades que os egressos do Mestrado em Desenvolvimento Regional procuraram para cursar Doutorado foram principalmente PUCRS, UFRGS e UFSC. A Tabela 11 também foi organizada em forma de ranking para ilustrar as 5 maiores ocorrências.

Tabela 11. Número de Mestres pelo PPGDR com Doutorado (5 maiores ocorrências)

\begin{tabular}{l|ccr}
\hline Organização de Ensino & Concluído & Em curso & \multicolumn{1}{c}{ Total } \\
\hline \multirow{2}{*}{$1^{\circ}$ UNISC-PPGDR } & 15 & 13 & 28 \\
\cline { 2 - 2 } & 2 & 1 & 3 \\
$2^{\circ}$ PUCRS & 9 & 2 & 11 \\
$3^{\circ}$ UFRGS & 7 & 2 & 9 \\
$4^{\circ}$ UFSC & 6 & 2 & 8 \\
$5^{\circ}$ UNISINOS & 3 & 2 & 5 \\
Total & 42 & 22 & 64 \\
\hline
\end{tabular}

Foram considerados 90 currículos (58 Concluídos e 32 em curso).

Fonte: Plataforma Lattes CNPq - Elaborado pelos autores. 
O Mapa 2 mostra a localização dos municípios em que os mestres e doutores pelo PPGDR atuam profissionalmente. Como no mapa anterior, os círculos proporcionais evidenciam a intensidade de ocorrências. Foram considerados 249 currículos de Mestres e 50 currículos de Doutores, que apresentavam os dados completos no primeiro semestre de 2014. Observa-se que os egressos atuam em diversas regiões do território brasileiro. Entretanto, é no município de Santa Cruz do Sul-RS que a maioria dos pós-graduados desenvolve suas atividades profissionais.

Na sequência, no Mapa 3 os dados apresentados nos dois primeiros mapas são representados em grupos, evidenciando que há casos em que os egressos retornam ao município em que cursaram a Graduação e casos em que passam a atuar profissionalmente em outro município. A maior concentração está no Rio Grande do Sul, no entanto chama a atenção que os limites nacionais são extrapolados. Outro elemento importante do mapa 3 refere-se à identificação das unidades territoriais que complementam as duas primeiras representações (Mapas 1 e 2). 

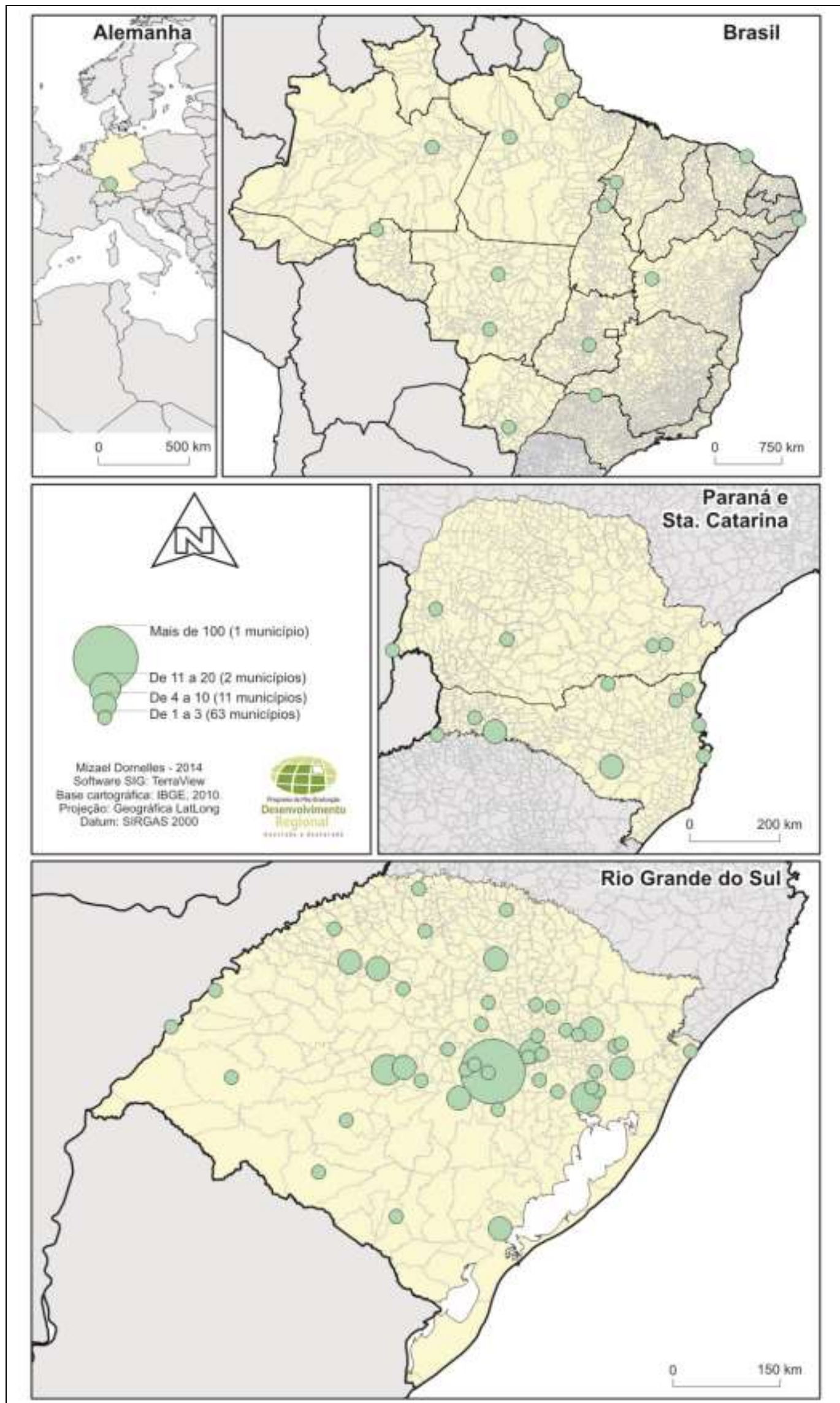

Mapa 2. Mestres e Doutores por município de atuação profissional Fonte: Elaborado pelos autores. 

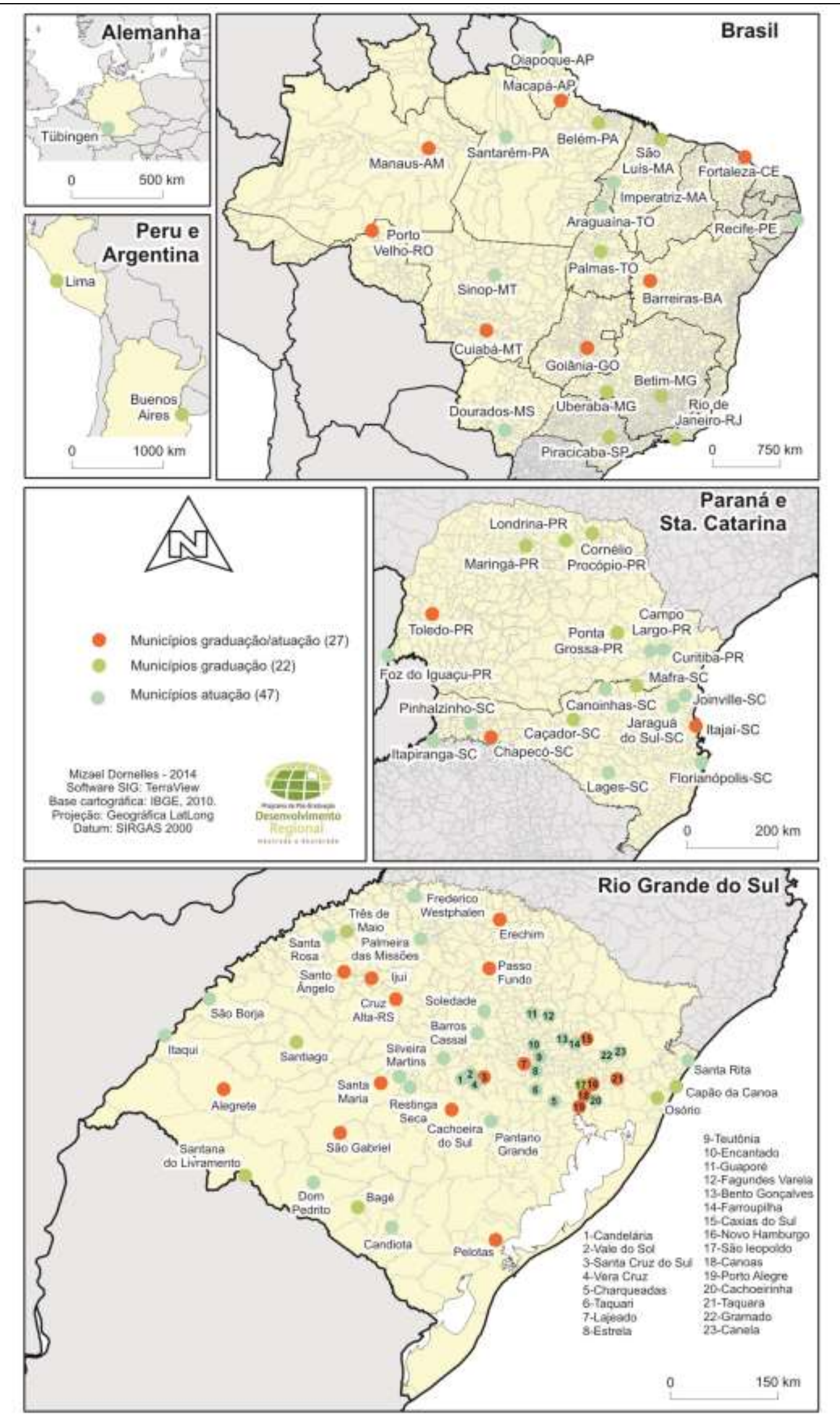

Mapa 3 Mestres e Doutores por município de Formação e Atuação Fonte: Elaborado pelos autores. 
A partir dos dados apresentados pode-se constatar que a procura pelo Programa vem se intensificando por parte de candidatos formados na Grande Área de Ciências Sociais Aplicadas (52,7\%), seguida da Grande Área de Ciências Humanas (21\%). Este dado expressa o esforço que o Programa vem fazendo no sentido de estabelecer um foco na sua perspectiva interdisciplinar, trabalhando temas voltados à análise e à promoção do Desenvolvimento Regional.

Outro dado importante refere-se às áreas de atuação dos egressos, notadamente concentrada em Universidades, seguida de atuação em órgãos públicos. Cabe destacar que o fato dos egressos atuarem basicamente em Universidades, não significa que se restrinjam a essa atividade. Ao contrário, grande parte deles tem atuação destacada em entidades, como os Conselhos Regionais de Desenvolvimento - COREDES e demais organizações de representação da sociedade civil, a partir de atividades de pesquisa e extensão, desenvolvidas no âmbito das suas respectivas Instituições.

A significativa concentração no município de Santa Cruz do Sul, por parte dos egressos do Programa, destacadamente por parte dos Mestres, expressa a realidade dos primeiros anos do Programa, período em que significativo número de docentes da UNISC buscaram o Mestrado em Desenvolvimento Regional para qualificarem-se profissionalmente. Esse quadro mudou a partir dos anos 2000, evidenciado pelos dados referentes aos egressos do Doutorado, cuja maioria está vinculada à Universidade Federal de Santa Maria.

Outro dado relevante refere-se ao fato de 31\% dos Mestres retornarem ao Programa para cursar o Doutorado em Desenvolvimento Regional. Este é, com certeza, um dado que confirma a qualidade do Programa.

\section{Considerações Finais}

Os dados apresentados ilustram a trajetória de 20 anos do PPGDR, que foi o primeiro Programa de Pós-Graduação Stricto Sensu da UNISC. Alicerçado na perspectiva interdisciplinar, o Programa contou inicialmente com quatro Áreas de Concentração, as quais, ao longo dos anos, contribuíram para o surgimento de outros Programas de Pós-Graduação (PPGs) Stricto Sensu na Instituição. Em 2014 a UNISC contava com oito PPGs Stricto Sensu, sendo que as bases dos mesmos encontram-se no PPGDR. Como exemplos, pode-se identificar os seguintes: a Área Sócio-Cultural contribuiu para a criação do PPG em Letras e em Educação; a Área Econômico-Organizacional contribuiu para o surgimento do PPG em Administração; a Área Tecno-Ambiental contribuiu para a criação dos PPGs em Tecnologia Ambiental e em Sistemas e Processos Industriais; e a Área PolíticoInstitucional contribuiu para a criação dos PPGs em Direito e em Promoção da Saúde.

Estas quatro Áreas de Concentração foram suprimidas em 2002, período em que o Programa restringiu o seu campo se atuação, sem abrir mão, entretanto, da perspectiva interdisciplinar. Os campos específicos que passaram a sustentar a perspectiva interdisciplinar do Programa, a partir de então, passaram a ser basicamente Economia, Geografia, Sociologia, Ciência Política e História. 
Não resta dúvida de que o maior desafio do Programa para o futuro continua sendo o fortalecimento da interdisciplinaridade, principalmente no campo da pesquisa, porque entende-se que é na pesquisa que se constrói a interação entre os campos específicos do saber, em torno de projetos e programas de ação, voltados à transformação da sociedade.

\section{REFERÊNCIAS}

ARAÚJO, Tânia Bacelar de. Ensaios sobre o desenvolvimento brasileiro: heranças e urgências. Rio de Janeiro: Revan, 2000.

BOISIER, Sergio. El desarollo territorial a partir de la construcción de capital sinergetico. REDES Revista do Desenvolvimento Regional, Universidade de Santa Cruz do Sul, v. 4, n. 1, jan.-abr. 1999.

BANCO DIGITAL DE TESES E DISSERTAÇÕES - BTD. Busca por teses $e$ dissertações. Universidade de Santa Cruz do Sul-UNISC, sem ano. Disponível em: <http://online.unisc.br/btd/busca_simples.htm>. Acessos em: abril, maio e junho de 2014.

CORRÊA, Roberto Lobato. Trajetórias geográficas. Rio de Janeiro: Bertrand Brasil, 1997.

LENCIONI, Sandra. Região e geografia. São Paulo: Edusp, 1999.

PLATAFORMA LATTES. Currículo Lattes. Conselho Nacional de desenvolvimento Científico e tecnológico - CNPq, sem ano. Disponível em:

<http://buscatextual.cnpq.br/buscatextual/busca.do?metodo=apresentar $>$. Acessos em: abril, maio e junho de 2014.

SANTOS, Milton. A natureza do espaço - técnica e tempo, razão e emoção. São Paulo: Hucitec, 1996.

Secretaria do PPGDR. Documentos diversos. 2014. 


\section{Sobre os autores}

Virginia Elisabeta Etges

Doutora em Geografia, Docente e Coordenadora do Programa de Pós-Graduação em Desenvolvimento Regional - UNISC.

Endereço: Av. Independência, 2293, Bloco 10/sala 1023, Bairro Universitário. CEP 96815-900 Santa Cruz do Sul - RS - Brasil.

E-mail: etges@unisc.br

\section{Mizael Dornelles}

Graduado em Geografia, mestrando em Desenvolvimento Regional - UNISC - Bolsista CAPES.

Endereço: Av. Independência, 2293, Bloco 10/sala 1023, Bairro Universitário. CEP 96815-900 Santa Cruz do Sul - RS - Brasil.

E-mail: geomiza@yahoo.com.br 